\title{
INTEGRITY REQUIREMENTS OF A WIND TURBINE TOWER
}

\author{
TÉLIO MENDES FERNANDES ${ }^{1}$, JoÃo CARLOS MENEZES ${ }^{2}$.
}

\author{
1. Stress Department, GKN Aerospace, Osborne Site, Ferry Road, East Cowes, Isle of Wight, PO32 6RA, \\ United Kingdom \\ E-mail:telio.mendesegknaerospace.com
}

\author{
2. Divisão de Engenharia Mecânica-Aeronáutica, Instituto Tecnológico de Aeronáutica, ITA, DCTA, \\ 12228-900, São José dos Campos, SP, Brazil \\ E-mail: menezes@ita.br
}

\begin{abstract}
Most large wind turbines currently installed use self-supporting steel tubular towers. The present study aims to perform a structural analysis of a $100 \mathrm{~kW}$ wind turbine tower, taking into consideration several structural integrity requirements. Among many requirements of the design of a tower, the analysis of free vibration has been performed. Details of static and elastic stability analysis are also presented. The integrity analysis was performed using the commercial software ANSYS. The height of the tower was defined as $24 \mathrm{~m}$. The tower has been designed as an assembly of four $6 \mathrm{~m}$ height modules connected by bolted joints. A special consideration of the module connections will be presented. Flanges are adopted to strengthen the tower modules end, having also the purpose of attaching the modules extremities by pre stressed bolts. Contact elements were adopted for the joint model. A distinct tool provided by ANSYS is the possibility of applying a preload to the connecting bolts. Under the condition of a load produced by the turbine blades thrust, the connected flanges tend to separate at the outer edge. One may obtain the state of deformation of the opened joint. Results of the stress analysis of the joints reveal a major stress concentration at the base of the bolts heads.
\end{abstract}

Keywords— Wind Turbine; Finite Elements; Vibrations; Structural Analysis

Resumo - A grande maioria das torres de geradores eólicos atualmente instaladas são tubulares e de aço. O presente estudo tem como objetivo analisar estruturalmente uma torre de um gerador eólico de $100 \mathrm{~kW}$, levando em consideração vários requisitos de integridade estrutural. Entre outros requisitos, a análise de vibração livre foi realizada. Detalhes da análise estática e de estabilidade elástica também são apresentados. A análise de integridade foi realizada utilizando o ANSYS. A altura da torre foi definida como $24 \mathrm{~m}$. A torre foi projetada como uma montagem de quatro módulos de $6 \mathrm{~m}$ de altura, conectados por juntas parafusadas. Os resultados da análise de tensão das juntas revelam uma tensão máxima na base das cabeças dos parafusos.

Palavras-chave— Turbina Eólica, Elementos Finitos, Vibrações, Análise Estrutural.

\section{Introduction}

This paper aims to contribute to the expansion of engineering studies in the area of alternative and renewable energy generation, specifically helping in the development of a methodology for the design of structures of tubular towers of wind generators.

For a 24 meters height wind turbine of $100 \mathrm{~kW}$, all the dynamic and static requirements are defined for the design of the tubular tower, and a methodology using finite elements is set up. The design is based primarily on the vibration modes of the tower that should not coincide with the frequency of the generator excitation. Thereafter the basic geometry is defined.

Thereon the static strength analysis and buckling is carried out, ending with the detailed analysis of the tower flanged pre stressed bolt joints modules, leading to the definitions of the amount of screws needed and the appropriate pretension load.

Due to the complexity of the structures and the non-linearity of the contacts between the modules of the structure, the finite element method, using the commercial software ANSYS for nonlinear structural analyzes, and RADIOSS for the linear analysis.

\section{Requirements}

In the design of the tower, the critical gust load at the generator and the excitation frequencies of the rotation generator and crossing of blades were considered.

For the sizing of the wind tower a wind generator of $100 \mathrm{~kW}$ having a height of $24 \mathrm{~m}$ was considered according to Donadon et al (2008). The generator project had a preliminary evaluation of characteristics of the blades through an optimization software for blades of wind generators. The wind generator nacelle presents 4 tons, including the blades, the critical gust load for a wind speed of $30 \mathrm{~m} / \mathrm{s}$ leading to a drag force was estimated to be $92 \mathrm{kN}$, which is a critical condition for static sizing of the tower. For the nominal wind velocity of $12.5 \mathrm{~m} / \mathrm{s}$ the blades speed ratio at $\lambda=6.759$, which corresponds to a rotation speed of $99 \mathrm{rpm}$, or an excitation frequency of $1.65 \mathrm{~Hz}$. Attention should also be given to the fact that, for reasons of aerodynamic disturbance produced by the passage 
of a blade near the tower, a frequency of three times the excitation frequency rotation of the generator, $1.65 \mathrm{~Hz}$, should also occur, i.e. $4.95 \mathrm{~Hz}$.

\section{Basic conception and structural analysis}

Recently, Mendes and Menezes (2010a) presented a study of sensitivity to design parameters which identified the diameter of the base of the tower ideal for adjusting the natural frequency of the tower away from the frequencies of excitation of the generator. From this, all the basic conception was defined: base diameter of $3.0 \mathrm{~m}$, top diameter of $1.8 \mathrm{~m}$, four flanged modules of $6.0 \mathrm{~m}$ height and wall thickness of $9.5 \mathrm{~mm}$ that should be checked trough the static analysis.

Figure 1 shows the first natural modes and frequencies of the wind tower designed. The first and second mode for this configuration are first order bending modes of $3.47 \mathrm{~Hz}$, which classifies the tower as flexible, placed between the blade passing frequency, $4.95 \mathrm{~Hz}$, and the rotational speed of the generator, $1.65 \mathrm{~Hz}$. The third and fourth modes are also bending, however, second-order modes of $20 \mathrm{~Hz}$, well away from the excitation frequencies of the wind generator.

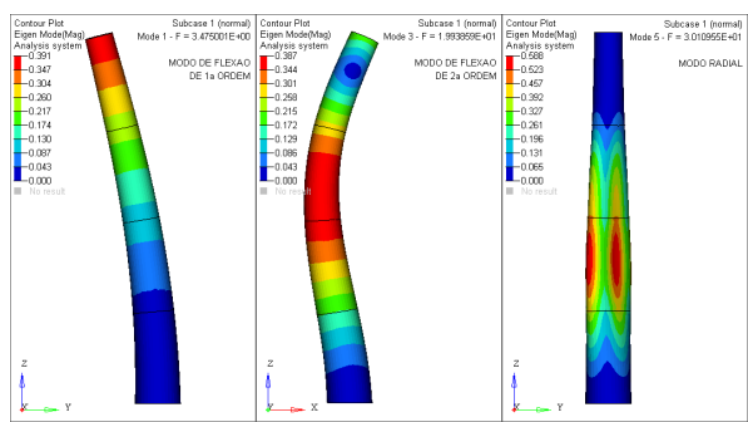

Figure 1. Eigenvector and eigenvalues of the tubular conical wind tower for modal analysis

Figure 2 shows results for the global stress static analysis for the critical gust drag load condition of $92 \mathrm{kN}$ in addition with the gravitational load also applied to evaluate the effects of the weight of the turbine and tower together with the wind load. From the results it is seen that the gravitational loads are negligible compared to the gust load. It could be considered conservative to neglect it as it reduces the tensioning loads acting in the module flanges. The figure presents separate results for the gravitational load, gust load and both together.

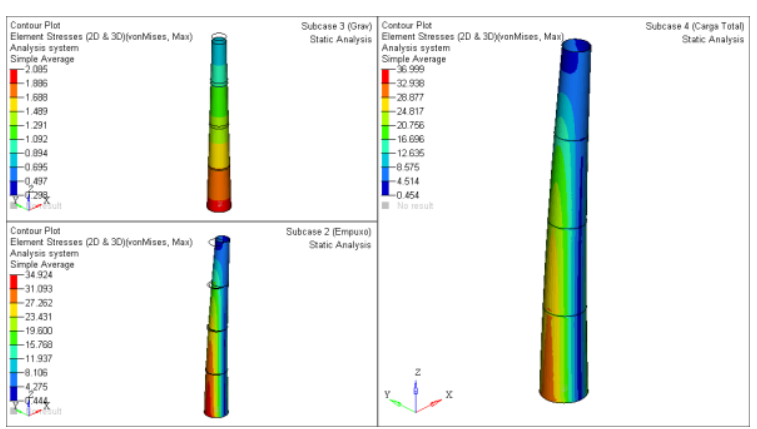

Figure 2. Global stress static analysis - von Mises stress $(\mathrm{MPa})$

Considering that, standard steel metallic plates have its yielding stress of almost $345 \mathrm{MPa}$, one may conclude that for static loads the structure has a high margin of safety. Structures of wind turbines should be designed to high cycling, higher than aeronautical structures e.g. Thereby, for the normal operating conditions, loads must be kept in low levels in order to avoid considering also the extreme amplifications dynamic loads in the count of the fatigue damage cycles.

Figure 3 shows the result of the buckling analysis for the critical gust load. Similarly to the stress static analysis of the structure, the weight of the structure has low influence on the results. The structure provides security for this requirement as it would be required a load 24 times greater than that to produce structural instability in the tower.

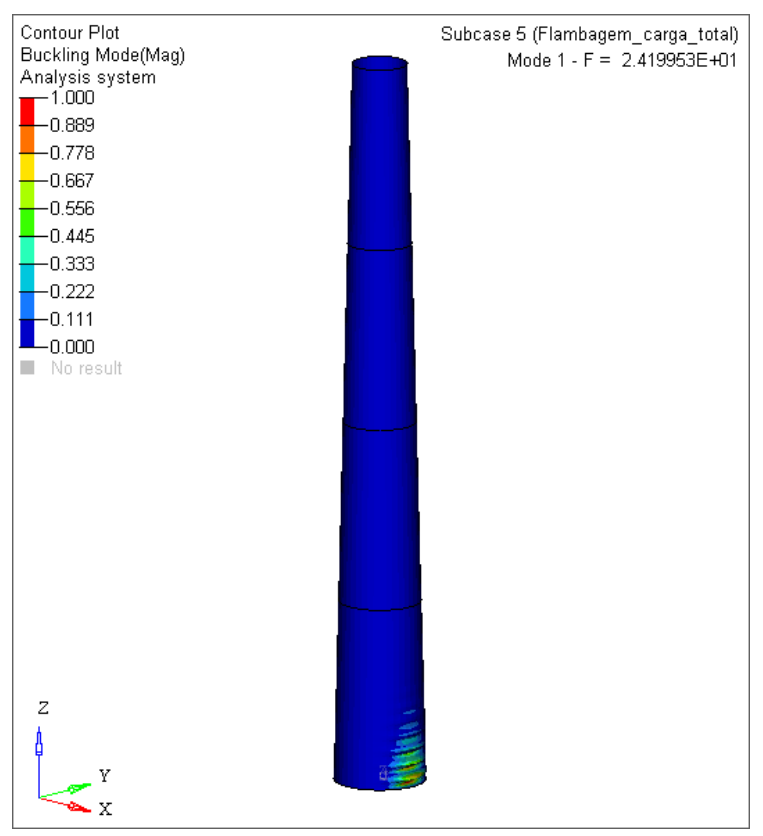

Figure 3. Buckling analysis 


\section{Bolted joint}

For the flanged bolted joints a detailed analysis was performed to validate the methodology for the sizing of the joint: thickness, number of bolts and pre tension load.

The ESDU 84039 (1986) presents an analytical method for analysis of flanged connections with pretensioned bolts under tensile load for estimating the stresses, deformation and the maximum load allowable for the joint based on experimental data. According to the ESDU 85021 (1995), pre-tensioned bolted joints must ensure two conditions: the bolts do not yield and the flanged joint does not open.

The procedure warns that this kind of analysis is a complex procedure resultant from the interaction of various elements stiffness. Thus, the procedure provides simplified models that illustrate the main effects of the many factors that influence the stresses and deflections in the joint.

The German Procedure, VDI2230 (2003), presents some analytical methods to evaluate the behavior of this joint to some restricted situations. It presents a method for calculating the bolt load increase as a proportion of load increase in the width of the wall of influence under these conditions. The axial load on the flanged joint and the effect of the moment due to the eccentricity of loading are considered separately. The axial load is assumed to be shared between the screw and the pre-tensioned flange in proportion to the stiffness of the load paths, which, in the case of flanges, are based on an area of the reduced cross section related to the compressed volume by the pre load. This procedure presents the disadvantage of being too conservative for low values of loading.

Schmidt and Neuper (1997) proposed a more sophisticated model identified as "Model C", a method that combines aspects of VDI2230 and considers the load on the screw so as to be as close as possible to the experimental results, which makes it a more realistic calculation, however increasing the complexity of calculating the loading.

The uniformity of loading of the screw around the tower depends on the accuracy of the contact surfaces between the coupling flange. Schmidt et al (1999) investigated the effects of various imperfections using a finite element model and iterative testing done with the tolerance levels allowed.

Shigley (1994) emphasizes one more point in the complexity of the analysis of this type of joint when it lists a table to some material friction coefficients.

To help on the understanding of this kind of joint, mainly for circular joints as found in wind turbine towers, finite element models were constructed to represent this complex non linear behavior with the objective to get a confident methodology for structural analysis for this kind of structures.

\section{Convergence model}

Mendes and Menezes (2010b) presented a study and all procedures to be considered in order to obtain accurate results from the analysis.

Figure 5 presents one of the steps of this study, where it was concluded as necessary for the convergence, that the full model should have the load applied in progressive steps. One should take into account the refinement on the model of the studied region, how to model the bolt head and its linkage to the flange, the non-linearity model of the contact faces, the friction between the surfaces and the iterative method for the nonlinear analysis to improve the convergence without jeopardize the results accuracy.

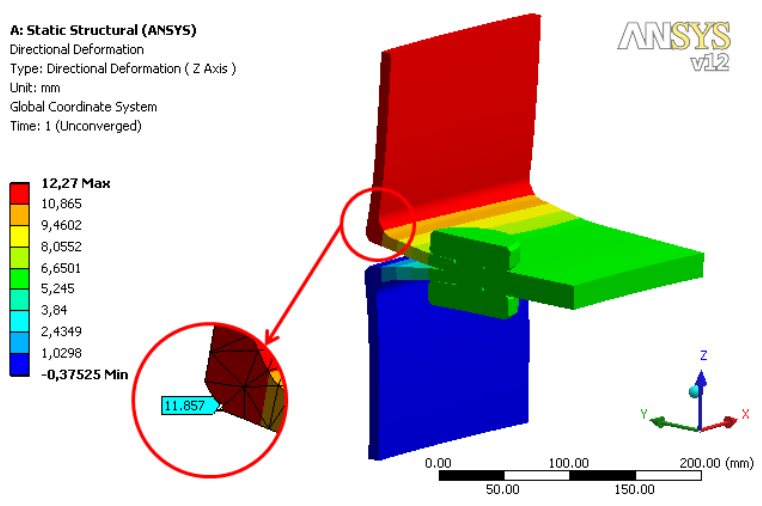

Figure 4. Reduced convergence model

Mendes (2012) presents the detailed analysis of the pre-tensioned flanged of a wind turbine tower. Figure 6 presents the global detailed model with the loads and boundary conditions built according to the definitions from the reduced convergence model.

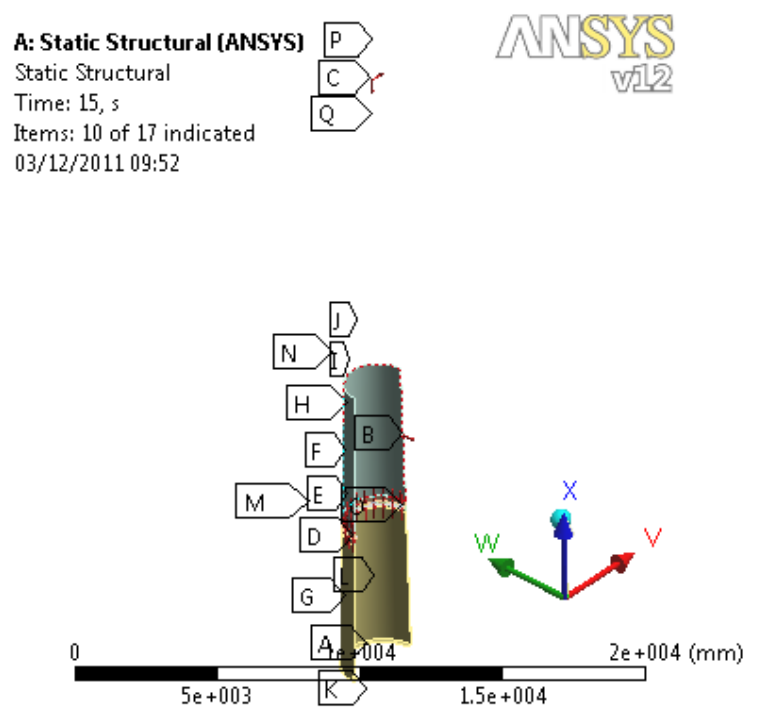

Figure 5. Symmetrical global model with loads and boundary conditions 
After forty-nine iterations, the global model with the gust load converged, as seen in Figure 7, where it is presented the convergence for each one of the fifteen sub steps of loads increments.

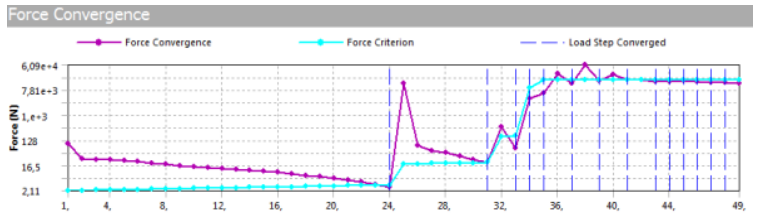

Figure 6. Convergence table

The results of the analysis are shown in Figures 7, 8 and 9, deformation, stress distribution over the critical bolt and stress distribution over the flange region, respectively.

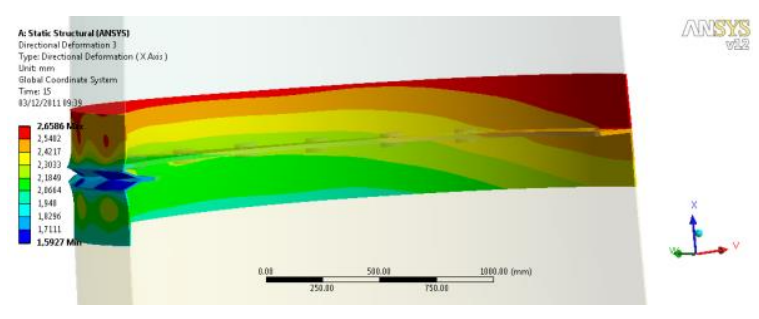

Figure 7. Deformation of the flange

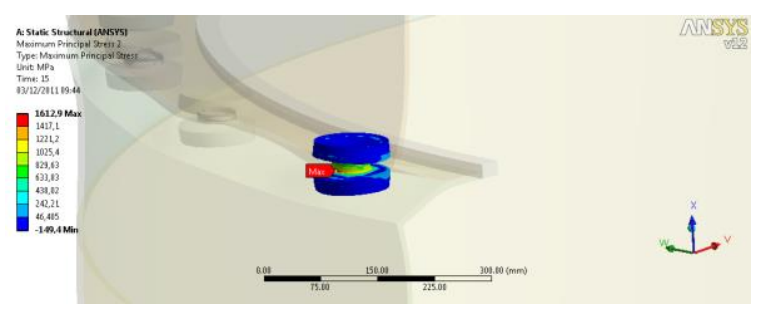

Figure 8. Critical bolt stress distribution
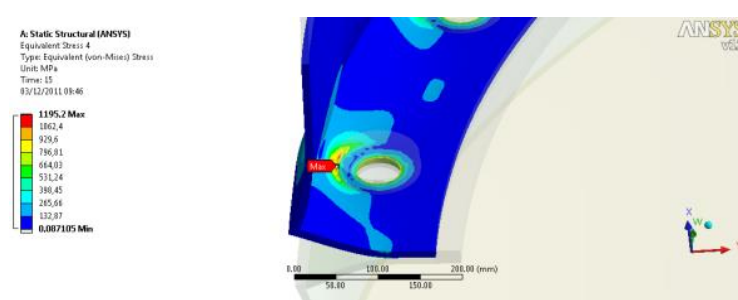

Figure 9. Flange stress distribution over the critical bolt

\section{Results comments}

These results are in line with the expected behavior, compared to a structure having one pre-tensioned bolt only. What can be evidenced is that ANSYS analyses for the pre-tensioned elements is a very useful tool to evaluate this kind of joint, since experimental data are not always available to an accurate analytical analysis.
To ensure this procedure for sizing wind turbines towers or similar structures it is recommended the calibration of the finite element models with some test data.

\section{References}

Donadon, M. V., Savanov, R., Menezes, J. C. and Lindolfo, A. M. F., 2008, "A numerical tool to design blades for horizontal axis wind turbines with variable geometry". In: National Congress of Mechanical Engineer, 5, Salvador.

Engineering Science Data Unit, 1986, ESDU 84039: Strength of angles and club-foot fittings (transmitting tensile loads). Hatfield.

Engineering Science Data Unit, 1995, ESDU 85021: Analysis of pre-tensioned bolted joints subject to tensile (separating) forces. London.

Mendes, T. F. and Menezes, J. C., 2010a, "Estudo de sensibilidade e dimensionamento estrutural de torres tubulares para geradores eólicos". In: Congresso Nacional de Engenharia Mecânica, 6, 2010, Campina Grande.

Mendes, T. F. and Menezes, J. C., 2010b, "Comportamento da ligação entre módulos flangeados de torres cilíndricas para geradores eólicos". AE601 Iniciação a Pesquisa. São José dos Campos: ITA.

Mendes, T. F., 2012, Dimensionamento de Torre Cônica Tubular de Gerador Eólico de $100 \mathrm{~kW}$, Master thesis, ITA, São José dos Campos.

Schmidt, H. and Neuper, M., 1997, On the elastostatic behaviour of an eccentrically tensioned l-joint with prestressed bolts. Stahlbau.

Schmidt, H., Winterstetter, T. A. and Kramer, M., 1999, "Non-linear elastic behaviour of imperfect, eccentrically tensioned 1-flange ring joints with prestressed bolts as basis for fatigue design". In: European Conference on Computational Mechanics.

Shigley, J. E., 1984, Elementos de máquinas. v. 1. Rio de Janeiro: LTC.

Verein Deutscher Ingenieure, 2003, VDI2230: systematic calculation of high duty bolted joints joints with one cylindrical bolt. 